\section{(6) OPEN ACCESS}

\title{
Injuries associated with long working hours among employees in the US mining industry: risk factors and adverse outcomes
}

\author{
Lee S Friedman, ${ }^{1}$ Kirsten S Almberg, ${ }^{2}$ Robert A Cohen ${ }^{\oplus 3,4}$
}

\begin{abstract}
- Additional material is published online only. To view please visit the journal online (http://dx.doi.org/10.1136/ oemed-2018-105558).
\end{abstract}

${ }^{1}$ School of Public Health, University of Illinois at Chicago, Chicago, Illinois, USA ${ }^{2}$ School of Public Health, Division of Environmental and Occupational Health Sciences, University of Illinois at Chicago, Chicago, Illinois, USA

${ }^{3}$ Environmental and Occupational Health Sciences, University of Illinois at Chicago Chicago, Illinois, USA

${ }^{4}$ Pulmonary and Critical Care Medicine, Northwestern University Feinberg School of Medicine, Chicago, Illinois, USA

\section{Correspondence to}

Dr Lee S Friedman, School of Public Health, University of Illinois at Chicago, Chicago, IL

Received 26 October 2018 Revised 5 March 2019 Accepted 24 March 2019 Published Online First 12 April 2019 60612, USA; Ifried1@uic.edu

\section{ABSTRACT}

Objectives The mining industry is increasingly adopting extended workdays of 10-12 hour shifts. Studies demonstrate that long work hours are associated with psychomotor impairments caused by fatigue and an increased risk of injury. However, studies involving miners remain limited. This analysis aimed to identify risk factors associated with long working hour injuries and to determine if long working hour incidents were associated with being killed or incidents involving multiple injured workers.

Methods Data from US Mine Safety and Health Administration Part 50 reports, 1983-2015, were used to identify long working hour injuries, which were defined as incidents occurring nine or more hours after the start of a shift.

Results A total of 52206 injuries (9.6\%) occurred during long working hours. The proportion of long working hour injuries increased from $5.5 \%$ of all injuries in 1983 to its peak in 2015 at $13.9 \%(p<0.001)$. Risk factors associated with long working hour injuries included irregular shift starts, being newly employed, employment by a contractor, metal/non-metal operations and mines with $<100$ employees. In two separate adjusted models, long working hour injuries were associated with a higher odds of death (adjusted OR $[a O R]=1.32 ; 95 \% \mathrm{Cl} 1.18$ to 1.48 ) and single incidents resulting in two or more workers injured $(\mathrm{aOR}=1.73$; $95 \% \mathrm{Cl} 1.58$ to 1.89 ).

Conclusions Long working hour injuries were associated with a lack of routine, being new at the mine and specific mining activities. An international shift towards using contract labour and extended workdays indicates that injuries during long working hours will likely continue to grow as a problem in the mining industry.

\section{INTRODUCTION}

The mining industry has changed dramatically over Check for updates

(c) Author(s) (or their employer(s)) 2019. Re-use permitted under CC BY-NC. No commercial re-use. See rights and permissions. Published by BMJ.

To cite: Friedman $L S$ Almberg KS, Cohen RA. Occup Environ Med 2019:76:389-395. the past four decades. Automation, changes in technologies for surveying and extracting commodities, improved enforcement and an increased adoption of hygiene practices within the industry ${ }^{12}$ have corresponded with a precipitous decline in fatality and injury rates over the past three decades in many countries. Despite these trends, mining remains high-risk relative to other industries. ${ }^{3}{ }^{4}$ However, an increased use of contractors to extract commodities from mines, the persistent long work weeks in the mining industry-averaging 47 hours or more

\section{Key messages}

What is already known about this subject?

- Longer shifts are associated with performance impairments and an increased risk of injury.

- However, prior research focusing on miners has reported that miners modify their activities when working long hours and do not show impairments in psychomotor performance.

- Because there are only a limited number of studies looking at long working hours and risk of injury among persons employed in the mining industry, it remains unclear if long working hours are associated with adverse outcomes, and there are no studies characterising risk factors associated with long working hour injuries in this industry.

What are the new findings?

- The proportion of injuries occurring 9+ hours into a shift has increased by almost threefold since 1983.

- Factors associated with change, lack of routine and being new at the mine were associated with injuries occurring 9+ hours into a shift among employees in the US mining industry between 1983 and 2015.

- Incidents occurring during long working hours were more likely to result in a death or multiple workers injured.

How might this impact on policy or clinical practice in the foreseeable future?

- The findings are disturbing given the international shift towards hiring more contract labour and the adoption of extended workdays from 8 to 10-12 hour shifts in the mining industry.

- Adoption of comprehensive fatigue risk management plans may help ameliorate the problem.

per week in the USA - and the increased adoption of extended workdays from 8 hour to 10-12 hour shifts may offset the potential gains in safety. ${ }^{5-7}$

The increase in longer shift hours is of particular concern because long shifts are associated with behavioural impairments caused predominately by fatigue. $^{8-11}$ Workers underestimate their fatigue, ${ }^{12}$ and fatigue is associated with an increased risk of 
incidents resulting in injury. ${ }^{13-15}$ Fatigue resulting from long working hours is associated with impaired response time, ${ }^{8} 1617$ vigilance/alertness, ${ }^{8} 18$ the ability to process information ${ }^{8}$ and muscle strength ${ }^{19}$; however, there are studies showing that long working hours have no impact on psychomotor functioning. ${ }^{20-23}$ In addition, long shifts in manual labour jobs are associated with lower job satisfaction, ${ }^{24}$ absenteeism ${ }^{25} 26$ and a decline in overall health. ${ }^{27}$

In the mining industry, longer cumulative work hours result in longer exposures to respiratory hazards and radiation, in addition to the increased risk of injury from fatigue. Several studies of miners have evaluated the role of extended shift work and show that miners appear to slow their pace of work when working long hours and show no significant changes in cognitive-behavioural performance, indicating that extended hours may have little impact on performance in miners. ${ }^{28-30}$ Currently, there are only a limited number of studies looking at long working hours and risk of injury among persons employed in the mining industry, ${ }^{5141531}$ but none of these studies characterise risk factors associated with long working hour injuries in this industry. The objectives of this study are to: (1) describe employee and mine practices associated with extended work hour injuries, (2) identify risk factors for injury among mining employees working long hours relative to injuries occurring through the first 8 hours and (3) determine if incidents occurring in mines involving persons working long hours are associated with a higher likelihood of being killed or incidents involving multiple workers injured.

\section{METHODS}

\section{Mine Safety and Health Administration (MSHA) data}

US employers in the mining industry are required to report work-related injuries and illnesses to the MSHA that 'require medical treatment or results in death or loss of consciousness or inability to perform all job duties on any workday after the injury or temporary assignment to other duties or transfer to another job'. ${ }^{32}$ For this study, we downloaded all Part 50 accident/injury data files submitted to MSHA between 1983 and $2015 .^{32}$ In addition, we also used data from the address and employment files to link data regarding production, mine level employment numbers and controlling company. ${ }^{32}$

\section{Inclusion criteria}

This study includes adults ages 18 years and older who suffered acute injuries and illnesses while working for a mine operator or contractor between 1983 and 2015. Out of the original 673539 incidents in the original dataset, we excluded 94297 cases comprising non-employees, minors (<18 years), cases with no reported injury and cases suffering from non-acute injuries and illnesses that are unlikely to have been caused during a single shift. These non-acute injuries and illnesses included lung disease, cumulative trauma disorders, cancer, occupational skin diseases or disorders, hearing loss and unspecified occupational diseases. There were also 33705 cases $(5.0 \%$ of total cases) that were excluded because they had missing information regarding their shift start and/or end times; these cases predominately included back injuries, hernias, overexertion injuries and minor injuries among employees working at quarries. Based on the given shift start time and incident time, we estimated the number hours an employee was on a shift at the time of the incident.

\section{Estimated long work hours}

Long working hour injuries in this study was defined as any injurious event reported to MSHA that occurred 9 or more hours into a worker's shift (also interchangeably referred to as extended work hours). As part of the analysis, we estimated the average annual crude acute injury incidence rate through the first 8 hours of work and the rate occurring 9 or more hours on the job per 100 full-time employees (FTEs). In order to estimate the cumulative extended hours worked in a mine, we used the number of total employees and total hours worked as reported by each mine. ${ }^{32}$ A detailed description of the methods is provided in the online supplementary materials.

\section{Covariates}

A descriptive analysis of the data showed that most shifts started during narrow windows of time in the morning (06:00-08:00), afternoon (14:00-16:00) and evening (22:00-00:00). We created a variable to account for irregular shifts that represent potential unscheduled shifts (eg, filling in for a sick coworker and emergencies). Shifts starting between 00:31-05:29, 08:31-13:29 and 16:31-21:29 were classified as irregular shift starts. This accounted for workers arriving 30 min early or late for shifts.

The dataset included information on each worker's total years of experience in mining, in the specific mine and for the job title at the time of the incident. If years of experience at the mine in which the incident occurred was missing, we imputed total years of experience for the employee because these two variables were highly correlated (Pearson's correlation $r=0.671$ ). For those missing both total years of experience in mining and in the specific mine, we imputed the years of experience in a specific job title. This added data on years of experience to 20152 cases out of the 35388 (6.5\% of 545537 cases used in the analysis) missing total years of experience in mining.

We coded workers whose regular job title and the job title at the time of the incident were different as workers not working in their primary occupation/job/role at time of injury.

\section{Statistical analysis}

For the descriptive analysis, workers were divided into four groups based on when the incident occurred as measured by the number of hours from the start of their shift: first 2 hours, 2-6 hours, 7-8 hours and $\geq 9$ hours. Descriptive statistics of injuries overall and distributions by demographic variables, mine experience, shift start, type of employer, commodity mined and injury outcomes were calculated. Appropriate parametric (Pearson's $\chi^{2}$ ) and non-parametric tests (Wilcoxon ranked-sum test) were used to evaluate bivariate relationships, and Tukey's pairwise comparison was used to compare difference in mean continuous variables across the four groups. The critical $\mathrm{p}$ value for the Tukey test was set at $\mathrm{p} \leq 0.001$ to account for multiple comparisons. Crude test for trend was used to calculate annual change in the proportion of long working hour injuries from 1983 to 2015.

For this analysis, we developed three multivariable logistic regression models using all of the data from 1983 to 2015. The first model evaluated predictors of injuries occurring during long working hours relative to injuries occurring through the first 8 hours (dependent variable). The next two models evaluated the relationship between incidents involving fatalities or multiple injured workers (dependent variables) and working 9 or more hours into a shift at the time of the incident (independent variable). For all three models, statistical evaluation of covariates, as well as a priori knowledge, was used to determine inclusion of covariates in the final models, similar to a manual stepwise 


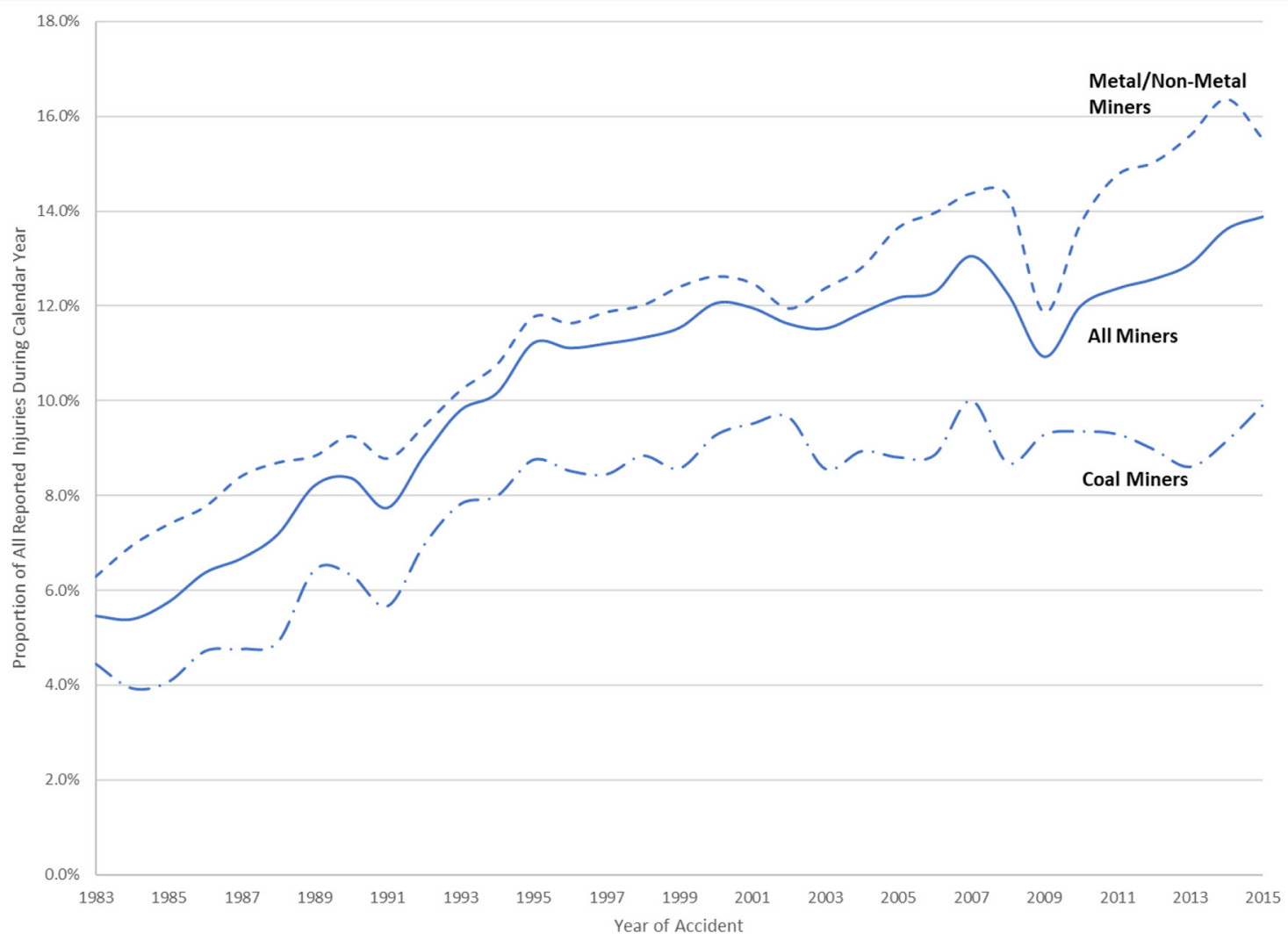

Figure 1 Increase in the proportion of injuries occurring during long working hours ( $\geq 9$ hours into a shift) by year of accident. Yearly data for all reported injuries to MSHA Part 50 Program in USA: 1983-2015. MSHA, Mine Safety and Health Administration.

model building approach. A two-sided p value less than 0.05 was considered statistically significant. ORs in the adjusted models are presented, including the 95\% CIs. No evidence of multicollinearity among the final independent variables was indicated in any of three models based on evaluation of standard errors and evaluation of variance of inflation and tolerance tests. We used SAS software for all statistical analyses (V.9.4).

\section{RESULTS}

A total of 52206 injuries occurred during long working hours as reported to MSHA from 1983 to 2015, representing 9.6\% of all injury reports. The proportion of long working hour injuries increased significantly during the period of observation from $5.5 \%$ of injuries in 1983 to its peak in 2015 at 13.9\% (test for trend $\mathrm{p}<0.001$; figure 1). Between 1983 and 2015, the proportion of long working hour-related injuries increased the most among employees involved in the extraction of metals from $3.8 \%$ to $17.8 \%$ and doubled in the following commodities: bituminous coal (change from $4.5 \%$ to $9.8 \%$ ), non-metals (change $4.5 \%-12.3 \%)$ and stone $(8.1 \%-15.1 \%) \%)$.

The crude average annual incidence rate per 100 FTE for injuries occurring 9 or more hours into a shift was 6.54 compared with 5.49 for injuries occurring through the first 8 hours of a shift. The crude incidence rates were substantially higher in operations mining for metal/non-metal commodities $(9+$ hours vs $<9$ hours: 9.14 vs 5.01 per 100 FTE) than in coal operations ( $9+$ hours vs $<9$ hours: 4.25 vs 6.23 per 100 FTE). When looking at specific mining operations, the largest difference in crude incidence rates were observed in surface operations that use brine pumping and other similar techniques for extracting metal/non-metal commodities $(9+$ hours vs $<9$ hours: 15.96 vs 4.71 per 100 FTE) (see online supplementary table). Table 1 provides descriptive data for injured workers by time of injury. New employees with less than 2 years of experience working at the mine site disproportionately suffered injuries during long working hours $(\mathrm{p}<0.001)$. Among those working for operators, $34.6 \%$ injured during long working hours had been employed at the mine for less than 2 years compared with $73.3 \%$ of those employed by contractors, and this observation persisted across all major commodity groups. Long working hour injuries were also more likely to involve workers who started their shifts between the hours of 23:00 and 06:59 $(p<0.001)$ or began their shifts at an irregular time $(\mathrm{p}<0.001)$. The proportion of long working hour injuries was also elevated among those not working at their primary occupation/job/role at the time of injury $(\mathrm{p}<0.001)$, but this was most pronounced among metal/non-metal workers.

\section{General product class}

Only $7.3 \%$ of all injuries involving coal mine employees occurred during long working hours, compared with $11.7 \%$ in metal mining, $12.0 \%$ in stone operations and $14.4 \%$ among sand and gravel workers. However, for most operators, approximately $1 / 3$ of the long working hour injuries involved employees who had worked at the mine for less than 2 years with the exception of sand and gravel operators, which was slightly higher (43.2\%; $\mathrm{p}<0.001)$. Metal and non-metal mines had disproportionately higher numbers of workers injured during long working hours while they were not working at their primary occupation/job/ role at time of injury (metal and non-metal operators: $8.1 \%$; non-coal contractor: 9.03\%; other classes: 4.7\%; $\mathrm{p}<0.001$ ). The proportion of workers with injuries occurring during long working hours was substantially higher among workers with 
Table 1 Characteristics of injured workers in mining by time of accident since shift began

\begin{tabular}{|c|c|c|c|c|c|}
\hline & N & During first 2 hours & Between hours 2 and 6 & Between hours 7 and 8 & $\begin{array}{l}\text { Long working hour cases } \\
9 \text { or more hours }\end{array}$ \\
\hline All cases & 545537 & 73284 & 327822 & 92225 & 52206 \\
\hline \multicolumn{6}{|l|}{ Gender } \\
\hline Male & 534311 & $71603(97.7 \%)$ & $321227(98.0 \%)$ & $90433(98.1 \%)$ & $51048(97.8 \%)$ \\
\hline Female & 11219 & $1680(2.3 \%)$ & $6590(2.0 \%)$ & $1791(1.9 \%)$ & $1158(2.2 \%)$ \\
\hline Unspecified & 7 & $1(0.0 \%)$ & $5(0.0 \%)$ & $1(0.0 \%)$ & $0(0.0 \%)$ \\
\hline Mean age (SD) & $\sim$ & $39.5(10.80)$ & $39.0(10.70)$ & $38.9(11.00)$ & $38.6(11.30)$ \\
\hline Mean total mine years experience (SD) & $\sim$ & $11.8(9.30)$ & $11.5(9.30)$ & $11.0(9.40)$ & $10.0(9.50)$ \\
\hline $\begin{array}{l}\text { Mean total mine years experience in this mine } \\
\text { (SD) }\end{array}$ & $\sim$ & $8.0(8.30)$ & $7.5(8.00)$ & $6.9(8.00)$ & $6.1(7.80)$ \\
\hline $\begin{array}{l}\text { Mean total mine years experience in this job } \\
\text { title (SD) }\end{array}$ & $\sim$ & $6.6(7.40)$ & $6.3(7.20)$ & $6.5(7.40)$ & $6.4(7.60)$ \\
\hline \multicolumn{6}{|l|}{ Time shift began } \\
\hline 07:00-14:59 & 263232 & $34532(47.1 \%)$ & $156623(47.8 \%)$ & $49161(53.3 \%)$ & $22916(43.9 \%)$ \\
\hline $15: 00$ to $22: 59$ & 127088 & $17085(23.3 \%)$ & $80287(24.5 \%)$ & $18661(20.2 \%)$ & $11055(21.2 \%)$ \\
\hline $23: 00$ to $06: 59$ & 155217 & $21667(29.6 \%)$ & $90912(27.7 \%)$ & $24403(26.5 \%)$ & $18235(34.9 \%)$ \\
\hline Irregular shift start* & 46841 & $6840(9.3 \%)$ & $22642(6.9 \%)$ & $6603(7.2 \%)$ & $10756(20.6 \%)$ \\
\hline Employed by contractor & 39687 & $4110(5.6 \%)$ & $21526(6.6 \%)$ & $7576(8.2 \%)$ & $6475(12.4 \%)$ \\
\hline $\begin{array}{l}\text { Not working in primary occupation/job/role at } \\
\text { time of injury }{ }^{-}\end{array}$ & 21846 & $2557(3.5 \%)$ & $12576(3.8 \%)$ & $3777(4.1 \%)$ & $2936(5.6 \%)$ \\
\hline Apprentice/trainee & 1514 & $182(0.2 \%)$ & $897(0.3 \%)$ & $276(0.3 \%)$ & $159(0.3 \%)$ \\
\hline \multicolumn{6}{|l|}{ Canvass or general product class } \\
\hline Anthracite coal & 4109 & $654(0.9 \%)$ & $2612(0.8 \%)$ & $608(0.7 \%)$ & $235(0.5 \%)$ \\
\hline Bituminous coal & 268266 & $35305(48.2 \%)$ & $171413(52.3 \%)$ & $41963(45.5 \%)$ & $19585(37.5 \%)$ \\
\hline Metal & 73991 & $9655(13.2 \%)$ & $43312(13.2 \%)$ & $12353(13.4 \%)$ & $8671(16.6 \%)$ \\
\hline Non-metal & 37487 & $5300(7.2 \%)$ & $22110(6.7 \%)$ & $6704(7.3 \%)$ & $3373(6.5 \%)$ \\
\hline Sand and Gravel & 39762 & $5185(7.1 \%)$ & $21116(6.4 \%)$ & $7749(8.4 \%)$ & $5712(10.9 \%)$ \\
\hline Stone & 121922 & $17185(23.4 \%)$ & $67259(20.5 \%)$ & $22848(24.8 \%)$ & $14630(28.0 \%)$ \\
\hline \multicolumn{6}{|c|}{$\begin{array}{l}\text { Number of injuries reported for accident/incident } \\
\text { categories }\end{array}$} \\
\hline 1 & 541820 & $72734(99.2 \%)$ & $325916(99.4 \%)$ & $91559(99.3 \%)$ & $51611(98.9 \%)$ \\
\hline 2 & 2379 & $308(0.4 \%)$ & $1301(0.4 \%)$ & $423(0.5 \%)$ & $347(0.7 \%)$ \\
\hline 3 & 425 & $57(0.1 \%)$ & $198(0.1 \%)$ & $97(0.1 \%)$ & $73(0.1 \%)$ \\
\hline 4 & 242 & $55(0.1 \%)$ & $93(0.0 \%)$ & $53(0.1 \%)$ & $41(0.1 \%)$ \\
\hline 5 or more & 671 & $130(0.2 \%)$ & $314(0.1 \%)$ & $93(0.1 \%)$ & $134(0.3 \%)$ \\
\hline Fatal injury & 2662 & $316(0.4 \%)$ & $1438(0.4 \%)$ & $549(0.6 \%)$ & $359(0.7 \%)$ \\
\hline Permanent disability, partial or total & 7505 & $953(1.3 \%)$ & $4560(1.4 \%)$ & $1303(1.4 \%)$ & $689(1.3 \%)$ \\
\hline $\begin{array}{l}\text { Median total lost work days (restricted and lost } \\
\text { work) (IQR) }\end{array}$ & 370997 & $5.0(0,31)$ & $5.0(0,30)$ & $4.0(0,28)$ & $4.0(0,26)$ \\
\hline
\end{tabular}

All reported injuries to MSHA Part 50 Program in USA: 1983-2015.

IQR $(25 \%, 75 \%)$

*Based on MSHA data, most shifts start in specific windows of time in the morning, afternoon and evening shifts (92.2\%). We accounted for irregular start times for each shift including shifts beginning between 00:31-05:29, 08:31-13:29 and 16:31-21:29, allowing for workers to arrive 30 min early or late for shifts in the morning (06:00-08:00), afternoon shifts (14:00-16:00) and night (22:00-00:00).

tThese are workers whose regular job title was different from the job title they were working at the time of injury. MSHA, Mine Safety and Health Administration.

irregular shift starts compared with regular shift starts across all major classes: coal operators $(25.2 \%$ vs $5.4 \%)$, coal contractors (23.9\% vs $12.4 \%)$, metal/non-metal operators (20.6\% vs $9.4 \%)$ and $\mathrm{metal} /$ non-metal contractors $(22.0 \%$ vs $15.1 \%)$.

\section{Predictors of long working hour injuries}

In the final adjusted model, risk factors associated with long working hour injuries included working on Sunday, having worked at the mine for less than 2 years, having an irregular shift start, working offsite at the time of the injury and being employed by a contractor rather than an operator (table 2). Compared with those employed by coal operations, all the other major commodity classes had higher odds of injuries during extended working hours, with the highest odds among sand and gravel employees. Long working hour injuries were more likely to involve falling from one level to another, being caught or struck by objects while conducting maintenance or repairs and being burned form welding. We also observed that the relationship between irregular shift starting times and long working hour injuries differed by the time of day an employee's shift began. In a model stratified by the time of day an employee's shift began (morning, afternoon, or evening), irregular shift starts were associated with long working hour injuries differentially during night shift (adjusted OR [aOR] $=2.04 ; 95 \%$ CI 1.95 to 2.13), morning shift $(\mathrm{aOR}=2.98 ; 95 \%$ CI 2.79 to 3.18$)$ and afternoon shift $(\mathrm{aOR}=5.61 ; 95 \%$ CI 5.36 to 5.87$)$. 
Table 2 Predictors of long working hour injuries occurring 9 or more hours into a shift. Multivariable logistic regression model * based on all reported injuries to MSHA Part 50 Program in U.S.: 1983-2015

\begin{tabular}{|c|c|c|}
\hline & $\begin{array}{l}\text { Adjusted OR } \\
(95 \% \mathrm{Cl})\end{array}$ & P-value \\
\hline Year of accident (1983-2015) & 1.02 (1.02 to 1.02$)$ & $<0.001$ \\
\hline Day of week of accident: sunday & 1.23 (1.17 to 1.28$)$ & $<0.001$ \\
\hline $\begin{array}{l}\text { Less than } 2 \text { years of experience at current } \\
\text { mine site }\end{array}$ & 1.13 (1.11 to 1.15$)$ & $<0.001$ \\
\hline Irregular shift start $†$ & 2.85 (2.78 to 2.92$)$ & $<0.001$ \\
\hline Employed by a contractor (not operator) & 1.64 (1.59 to 1.69$)$ & $<0.001$ \\
\hline \multicolumn{3}{|l|}{$\begin{array}{l}\text { Canvass or class of commodity mined (based } \\
\text { on industry code) }\end{array}$} \\
\hline Anthracite and bituminous coal & Ref & \\
\hline Metal & 1.52 (1.48 to 1.56$)$ & $<0.001$ \\
\hline Non-metal & 1.22 (1.17 to 1.26$)$ & $<0.001$ \\
\hline Sand and gravel & 1.71 (1.66 to 1.77$)$ & $<0.001$ \\
\hline Stone & $1.56(1.52$ to 1.59$)$ & $<0.001$ \\
\hline \multicolumn{3}{|l|}{ Mechanism or activity at time of accident } \\
\hline $\begin{array}{l}\text { Ambient temperature heat } \\
\text { related: atmosphere or environment }\end{array}$ & 1.96 (1.66 to 2.30$)$ & $<0.001$ \\
\hline $\begin{array}{l}\text { Fall from: headframe, derrick, tower, } \\
\text { ladder, machine, vehicle, equip, piled } \\
\text { material, scaffolds, walkways and } \\
\text { platforms. }\end{array}$ & $1.25(1.21$ to 1.30$)$ & $<0.001$ \\
\hline Flash burns (welding) & 2.08 (1.85 to 2.33$)$ & $<0.001$ \\
\hline $\begin{array}{l}\text { Caught in/between/under running } \\
\text { meshing objects, struck by flying objects } \\
\text { and struck against moving objects while } \\
\text { the employee conducting maintenance } \\
\text { or repairs }\end{array}$ & $1.24(1.13$ to 1.35$)$ & $<0.001$ \\
\hline Mine fire & 1.74 (1.09 to 2.77$)$ & 0.021 \\
\hline Injury occurred offsiteł & 1.32 (1.12 to 1.54$)$ & $<0.001$ \\
\hline $\begin{array}{l}\text { Employee was not working at their regular } \\
\text { job at time of injury§ }\end{array}$ & 0.89 (0.85 to 0.94$)$ & $<0.001$ \\
\hline \multicolumn{3}{|l|}{$\begin{array}{l}\text { Mine size category (average number of } \\
\text { employees in year of accident) }\end{array}$} \\
\hline Less than 20 & 1.52 (1.48 to 1.57$)$ & $<0.001$ \\
\hline $20-49$ & $1.33(1.30$ to 1.37$)$ & $<0.001$ \\
\hline $50-99$ & 1.17 (1.14 to 1.21$)$ & $<0.001$ \\
\hline $100-199$ & 0.99 (0.96 to 1.02$)$ & 0.625 \\
\hline 200 or more & Ref & \\
\hline
\end{tabular}

${ }^{*}$ All the variables in the table represent the variables included in the final multivariable model. Sex and age were insignificant in the final multivariable model and were excluded.

tBased on MSHA data, most shifts start in specific windows of time in the morning, afternoon and evening shifts (92.2\%). We accounted for irregular start times for each shift including shifts beginning between 00:31-05:29, 08:31-13:29 and 16:31-21:29, allowing for workers to arrive 30 min early or late for shifts in the morning (06:00-08:00), afternoon shifts (14:00-16:00) and night (22:00-00:00). ¥These include injuries to employees off of the mine property.

$\S$ These are workers whose regular job title was different from the job title they were working at the time of injury.

MSHA, Mine Safety and Health Administration.

\section{Association between extended work hour injuries and fatalities and multiple injured workers}

In two separate adjusted models (table 3 ) evaluating the odds of an incident involving a fatality or multiple injured workers as separate outcome variables, incidents involving long working hour injuries were strongly associated with a higher odds of an incident involving a fatality $(\mathrm{aOR}=1.32 ; 95 \%$ CI 1.18 to 1.48$)$ as well as single incidents resulting in two or more workers injured (OR $=1.73 ; 95 \% \mathrm{CI} 1.58$ to 1.89$)$.
Table 3 Association of between long working hour injuries occurring nine or more hours into a shift and adverse health outcomes

\begin{tabular}{lll}
\hline Outcome variable & OR $(95 \% \mathrm{Cl})$ & P-value \\
\hline Incident resulted in fatal injury to worker & & \\
$\quad$ Crude model & $1.48(1.32$ to 1.65$)$ & $<0.001$ \\
Adjusted model $^{*}$ & $1.32(1.18$ to 1.48$)$ & $<0.001$
\end{tabular}

Incidents resulting in injuries to two or

more workers

$\begin{array}{lll}\text { Crude model } & 1.81(1.66 \text { to } 1.98) & <0.001 \\ \text { Adjusted model } t & 1.73(1.58 \text { to } 1.89) & <0.001\end{array}$

Logistic regression models based on all reported injuries to MSHA Part 50 Program in USA: 1983-2015.

*Adjusted for year of accident, sex, age, total years of experience in current mine $<2$ years, apprentice/trainee, employed by a contractor, canvass or class of commodity mined and number of employees at mine.

†Adjusted for year of accident, sex, total years of experience in current mine $<2$ years, employed by a contractor, canvass or class of commodity mined, not working at their primary occupation/job/role at time of injury, injury occurred offsite and number of employees at mine.

MSHA, Mine Safety and Health Administratio n

\section{DISCUSSION}

In this study, we found that factors associated with change, lack of routine, small mine operations and being new at the mine were associated with injuries occurring during long working hours relative to injuries occurring through the first 8 hours. Furthermore, incidents occurring during long working hours were more likely to result in a death or incidents involving multiple injured workers. This finding is disturbing given that US miners continue to work extended shifts with an average in excess of 47 hours per week, unlike the general US workforce where average work hours have declined to 38.5 hours per week. ${ }^{33}$ In this study, we observed a steady annual increase in the proportion of injuries occurring during long working hours that mirrors a trend reported internationally as more mining operations move towards longer shifts. An added dynamic is the fourfold increase in the proportion of reported injuries among persons employed by contractors as opposed to those working directly for mine operators; employees of contractors were more likely to be injured during long working hours. Working for contractors is associated with working extended hours and irregular shifts, ${ }^{34}$ and the use of contract labour has been reported to be associated with inadequate training, lower compliance with occupational safety laws and higher injury rates. ${ }^{535}$

The MSHA Part 50 data only have information on shift start and end times. Studies have demonstrated that it is important to also consider the cumulative work hours in a week, the pattern of shifts prior to the incident (rotating vs fixed), frequency of breaks during a shift, level of ambient noise and sleep quality among the affected workers. ${ }^{1436}{ }^{37}$ In the present study, we are unable to distinguish whether the risk of injury is associated exclusively with long working hours or is caused by cumulative disruptions in the workers' shifts over a longer period of time preceding the incident or caused by poor sleep quality. However, the findings from this analysis are consistent with studies conducted among other occupations and industries ${ }^{13-15}$ as well as analyses on miners that only indirectly evaluated the role of long working hours. ${ }^{5}{ }^{14} 15$ Muzaffar $e t$ al focused their MSHA Part 50 analysis on the relationship between fatal injuries and employment by contractors and reported a nearly identical adjusted OR for the relationship between long working hours and fatalities $\left(\mathrm{aOR}=1.43\right.$; for years 1998-2007). ${ }^{5}$ Physical and mental fatigue detrimentally impacts quality of cognitive 
performance, resulting in slower processing time and premature responses. ${ }^{816-18} 38$ The impact on novel tasks is even more pronounced. This may explain the association between variables characterising inexperience, change and lack of routine with long working hour injuries.

Based on the crude average annual incidence rates and the multivariable model, the risk of injury during long working hours was greater in non-coal mining operations, with the strongest association found in sand and gravel operations. The MSHA Part 50 injury and illness reports showed that employees in coal mining compared with employees of other commodities were less likely to be employed by contractors $(6.9 \%$ vs $7.9 \% ; \mathrm{p}<0.001)$, have irregular shift starts $(6.4 \%$ vs $10.2 \%$; $<0.001)$ or involve employees with less than 2 years of experience at the mine (31.0\% vs $34.4 \%)$. Coal mining employees compared with metal/non-metal employees also had more mining years of experience on average (13.1 vs 9.4 years). In addition, the increase in the proportion of long working hour-related injuries appears to be static since 1995 among coal mining employees (figure 1). While the various risk factors listed above are significantly lower among coal workers, the differences are not pronounced. This indicates that the explanation for the lower observed risk among coal mining employees is likely attributable to multiple factors including the fact that coal mines tend to employ two to three times more workers on average compared with metal/non-metal operations. ${ }^{32}$ Prior studies have shown that smaller operations have higher injury rates. ${ }^{39}$ The present study showed that mining operations with fewer than 20 employees were the most strongly associated with long working hour-related injuries. It is unlikely that coal mining is a safer mining process, but rather that it presently has fewer risk factors within the industry.

There are several potential limitations to this study. Data on cumulative long work hours were not available in the MSHA data. We had to rely on an estimate of total hours employees worked 9+ hours. However, it is possible that some employees may have worked extended hours during a single shift but not necessarily exceeded a cumulative 40 hours work week, which would result in an undercount of the total extended hours worked and overestimate the rate for injuries occurring during long working hours. However, since the average work week in the mining industry has remained in excess of 47 hours, the undercount of extended work hours is likely not as pronounced as we would expect if we were evaluating other industries where the average work week is at or under 40 hours, such as the retail industry. A second limitation is that the MSHA Part 50 reports rely on employer reporting of injuries and illnesses. Employers in the mining industry have been shown to under-report injuries and illnesses to MSHA, ${ }^{40}$ and under-reporting is more pronounced among smaller operators. ${ }^{40} \mathrm{~A}$ third limitation involves the imputation of data for cases missing years of experience at the mine. Only a small proportion were missing years of experience at the mine in the final dataset (6.5\%). A sensitivity model using the original data for years of experience at the mine without imputation was performed, and the adjusted OR for workers with less than 2 years of experience at the current mine changed very little $(\mathrm{aOR}=1.15 ; 95 \% \mathrm{CI} 1.13$ to 1.18$)$. A final important limitation is that mining practices have changed a lot during the period of 1983-2015, as well as the medical transport and care of injured workers. In every model, year of injury (trend) was significant. The potential confounding would likely impact the model looking at fatal injuries the most. In this model, the trend variable shows a decline in the odds of fatal injury during the years of follow-up $(\mathrm{aOR}=0.85$ per 10 years of change), which coincides with an improvement in trauma care over this period.

\section{Conclusions}

Over the past several decades, we have seen an international shift towards more contract labour and an adoption of extended workdays from 8 to $10-12$ hour shifts in the mining industry. This coincides with the persistence of long work weeks averaging 47 hours per week in the USA. Given this trend, injury events during long shifts will likely continue to grow. Adoption of comprehensive fatigue risk management plans may help ameliorate the problem. These plans should engage management, Human Resources (HR) personnel and miners on multiple issues including protective workrest practices during shifts, improving working environments at the end of shifts to increase worker alertness (eg, lighting and temperature), offsetting workload demands caused by workforce depletion (ie, absent/sick/injured workers), ensuring safe working temperatures, managing noise exposure and providing adequate hydration and energy supply to workers during shifts which coincides with work-rest practices.

Long working hours appear to be an important risk factor associated with injury events, but our study was unable to determine whether this risk was caused by long working hours alone, or if it is caused by the cumulative work hours in a week, the pattern of shifts prior to the incident (rotating vs fixed), frequency of breaks during a shift, level of ambient noise and sleep patterns/ quality among the affected workers. ${ }^{14} 3637$ Further research is required to better inform fatigue management plans within the mining industry.

Contributors The undersigned author warrants that the article is original, is not under consideration by another journal and has not been published previously. The authors have read and approve this manuscript for publication. All authors meet the criteria for authorship stated in the Uniform Requirements for Manuscripts Submitted to Biomedical Journals. LSF had full access to all of the data in the study and takes responsibility for the integrity of the data and the accuracy of the data analysis. LSF was involved in the conception and design, acquisition of data, analysis and interpretation of the data, drafting of the article and statistical expertise. KSA was involved in the acquisition of data, conception and design, analysis and interpretation of the data and review of the written manuscript. RAC was involved in the conception and design, analysis and interpretation of the data and review of the written manuscript.

Funding This research was supported in part by funding from The Alpha Foundation for the Improvement of Mining Safety and Health, Inc. This project was also partially funded through the NIOSH surveillance program. Additional funding was provided in part by the Centers for Disease Control and Prevention through a U60OH010905 grant.

Disclaimer The views, opinions and recommendations addressed herein are solely those of the authors and do not imply any endorsement by the Alpha Foundation, its directors and staff. And, the views expressed in manuscript do not necessarily reflect the official policies of the Centers for Disease Control and Prevention or the Department of Health and Human Services.

Competing interests None declared.

Patient consent for publication Not required.

Ethics approval The University of Illinois at Chicago IRB approved this work (\# 2013-0714).

Provenance and peer review Not commissioned; externally peer reviewed.

Open access This is an open access article distributed in accordance with the Creative Commons Attribution Non Commercial (CC BY-NC 4.0) license, which permits others to distribute, remix, adapt, build upon this work non-commercially, and license their derivative works on different terms, provided the original work is properly cited, appropriate credit is given, any changes made indicated, and the use is non-commercial. See: http://creativecommons.org/licenses/by-nc/4.0/.

\section{REFERENCES}

1 Metals SNL, U.S M, Market M, et al. Prepared for The National Mining Association. London, England 2014 https://nma.org/wp-content/uploads/2016/09/NMA_Report_ Mines_to_Market_FINAL.pdf (accessed May 31, 2018).

2 Hoovers. Mining Industry Profile. http://subscriber.hoovers.com/H/industry360/ businessChallenges.html?industryld=1474 (accessed 31 May, 2018). 
3 U.S. Department of Labor. Mine Safety and Health Administration (MSHA). Fatality and Injury Rates: MNM US Mines - Fatality and All-Injury Rates CY 1977 - 2015. https:// www.msha.gov/sites/default/files/Data_Reports/Charts/MNM_US_Mines___Fatality_ and_All-Injury_Rates_CY_1-5-17.pdf (accessed 31 May, 2018).

4 U.S. Department of Labor. Mine Safety and Health Administration (MSHA). Fatality and Injury Rates: Coal US Mines - Fatality and All-Injury Rates CY 1977 - 2015. https:// www.msha.gov/sites/default/files/Data_Reports/Charts/Coal_US_Mines___Fatality_ and All-Injury Rates_CY 1-5-17.pdf (accessed 31 May, 2018).

5 Muzaffar $\mathrm{S}$, Cummings K, Hobbs $\mathrm{G}$, et al. Factors associated with fatal mining injuries among contractors and operators. J Occup Environ Med 2013;55:1337-44.

6 Duchon JC, Keran CM, Nelson BC, et al. Extended Workdays in an Underground Mine: Work Performance Analysis. Report of Investigations 9526. US Department of Interior. US Bureau of Mines. Spokane, WA 1994.

7 U.S. Department of Labor. Bureau of Labor Statistics. Current Population Survey. (Unadj) Average Hours, At Work in Mining Industries, Wage and Salary Workers (series LNU02033258). https://www.bls.gov/cps/home.htm (accessed 31 May, 2018).

8 Proctor SP, White RF, Robins TG, et al. Effect of overtime work on cognitive function in automotive workers. Scand J Work Environ Health 1996;22:124-32.

9 Son M, Kong JO, Koh SB, et al. Effects of long working hours and the night shift on severe sleepiness among workers with 12-hour shift systems for 5 to 7 consecutive days in the automobile factories of Korea. J Sleep Res 2008;17:385-94.

10 Virtanen $\mathrm{M}$, Ferrie JE, Gimeno D, et al. Long working hours and sleep disturbances: the Whitehall II prospective cohort study. Sleep 2009;32:737-45.

11 Salo P, Ala-Mursula L, Rod NH, et al. Work time control and sleep disturbances: prospective cohort study of Finnish public sector employees. Sleep 2014;37:1217-25.

12 Sabbagh-Ehrlich S, Friedman L, Richter ED. Working conditions and fatigue in professional truck drivers at Israeli ports. Inj Prev 2005;11:110-4.

13 Hänecke K, Tiedemann S, Nachreiner F, et al. Accident risk as a function of hour at work and time of day as determined from accident data and exposure models for the German working population. Scand I Work Environ Health 1998;24 Suppl 3:43-8.

14 Folkard S, Lombardi DA. Modeling the impact of the components of long work hours on injuries and "accidents". Am J Ind Med 2006;49:953-63.

15 Chimamise C, Gombe NT, Tshimanga M, et al. Factors associated with severe occupational injuries at mining company in Zimbabwe, 2010: a cross-sectional study. Pan Afr Med J 2013:14:5.

16 Mitler MM, Carskadon MA, Czeisler CA, et al. Catastrophes, sleep, and public policy: consensus report. Sleep 1988;11:100-9.

17 Ferguson SA, Kennaway DJ, Baker A, et al. Sleep and circadian rhythms in mining operators: limited evidence of adaptation to night shifts. Appl Ergon 2012;43:695-701.

18 Macdonald W, Bendak S. Effects of workload level and 8- versus 12-h workday duration on test battery performance. Int J Ind Ergon 2000;26:399-416.

19 Rosa RR, Bonnet MH, Cole LL. Work schedule and task factors in upper-extremity fatigue. Hum Factors 1998;40:150-8.

20 Smith L, Totterdell P, Folkard S. Shiftwork effects in nuclear power workers: A field study using portable computers. Work Stress 1995:9(2-3):235-44.

21 Schroeder DJ, Rosa RR, Witt LA. Some effects of 8-vs. 10-hour work schedules on the test performance/alertness of air traffic control specialists. Int I Ind Ergon 1998;21:307-21.

22 Lowden A, Kecklund G, Axelsson J, et al. Change from an 8-hour shift to a 12-hour shift, attitudes, sleep, sleepiness and performance. Scand I Work Environ Health 1998;24 Suppl 3:69-75.
23 Faber A, Strøyer J, Hjortskov N, et al. Changes in physical performance among construction workers during extended workweeks with 12-hour workdays. Int Arch Occup Environ Health 2010;83:1-8.

24 Nakata A. Long working hours, job satisfaction, and depressive symptoms: a community-based cross-sectional study among Japanese employees in small- and medium-scale businesses. Oncotarget 2017;8((32)):53041-52.

25 Baker A, Heiler K, Ferguson SA. The impact of roster changes on absenteeism and incident frequency in an Australian coal mine. Occup Environ Med 2003;60:43-9.

26 Westerlund H, Alexanderson K, Akerstedt T, et al. Work-related sleep disturbances and sickness absence in the Swedish working population, 1993-1999. Sleep 2008;31:1169-77.

27 De Raeve L, Jansen NW, Kant IJ. Health effects of transitions in work schedule, workhours and overtime in a prospective cohort study. Scand I Work Environ Health 2007;33:105-13.

28 Duchon JC, Keran CM, Smith TJ. Extended workdays in an underground mine: a work performance analysis. Hum Factors 1994;36:258-68.

29 Duchon JC, Smith TJ, Keran CM, et al. Psychophysiological manifestations of performance during work on extended workshifts. Int I Ind Ergon 1997;20:39-49.

30 Hossain JL, Reinish LW, Heslegrave RJ, et al. Subjective and objective evaluation of sleep and performance in daytime versus nighttime sleep in extended-hours shiftworkers at an underground mine. J Occup Environ Med 2004;46:212-26.

31 Boniface R, Museru L, Munthali V, et al. Occupational injuries and fatalities in a tanzanite mine: Need to improve workers safety in Tanzania. Pan Afr Med J 2013;16:120.

32 U.S. Department of Labor. Mine Safety and Health Administration. Mining Industry Accident, Injuries, Employment, and Production Data. https://www.cdc.gov/niosh/ mining/data/default.html (accessed 19 December, 2017).

33 US Department of Labor. Bureau of Labor Statistics. Table 21: Persons at work in nonagricultural industries by class of worker and usual full- or part-time status. Downloaded data for years 2000-2015. https://www.bls.gov/cps/tables.htm (accessed 31 May, 2018)

34 Grosch JW, Caruso CC, Rosa RR, et al. Long hours of work in the U.S.: associations with demographic and organizational characteristics, psychosocial working conditions, and health. Am J Ind Med 2006;49:943-52.

35 Cummings KJ, Kreiss K. Contingent workers and contingent health: risks of a modern economy. JAMA 2008;299:448-50.

36 Saremi M, Rohmer 0, Burgmeier A, et al. Combined effects of noise and shift work on fatigue as a function of age. Int I Occup Saf Ergon 2008;14:387-94.

37 International Labor Organization. Conditions of Work and employment Series No. 31: Working Time, Health, and Safety: a Research Synthesis Paper prepared by Philip Tucker and Simon Folkard, on behalf of Simon Folkard Associates Ltd. Geneva, Switzerland, 2012.

38 Lieberman HR, Niro P, Tharion WJ, et al. Cognition during sustained operations: comparison of a laboratory simulation to field studies. Aviat Space Environ Med 2006;77:929-35.

39 Page K. Blood on the coal: the effect of organizational size and differentiation on coal mine accidents. J Safety Res 2009;40:85-95.

40 Almberg KS, Friedman LS, Swedler D, et al. Mine Safety and Health Administration's Part 50 program does not fully capture chronic disease and injury in the Illinois mining industry. Am J Ind Med 2018:61:436-43. 